\title{
Maxillofacial surgery in patients with obstructive sleep apnea and snoring
}

\author{
Tonchev Ts., Milkov M., Nedev P. \\ Medical University „Prof. P. Stoianov“ - Varna
}

\begin{abstract}
The present survey systematizes the modern foreign literature devoted to the recent advances in the surgical management of the patients with obstructive sleep apnea and snoring. The results from the application of a variety of contemporaty methods are briefly described. A special attention is paid to the maxillomandibular advancement that represents the most common maxillofacial surgical
\end{abstract}

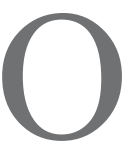

bstructive sleep apnea is a relatively common sleep breathing disorder that is popularly associated with snoring and excessive daytime sleepiness. A surgical approach to its treatment remains an area of intense debate, both within and without the surgical community itself. Although continuous positive airway pressure therapy remains the gold standard for the treatment of obstructive sleep apnea, surgery may be indicated to facilitate conservative management and/or improve compliance in cases where the latter is poorly tolerated.

G. Dimitroulis (1997) reviews the role of the oral and maxillofacial surgeon in the recognition and management of this disorder. According to this author, surgery of the upper airways includes uvulopalatopharyngoplasty and partial glossectomy while specidic maxillofacial surgery incorporates geniotubercle advancement (or geniotomy) and/or hyoid suspension; advancement genioplasty; mandibular advancement and/or advancement genioplasty as well as maxillomandibular advancement and/or advancement genioplasty.

Historically, tracheostomy is the first surgical modality used for the treatment of obstructive technique in this interdisciplinary field. The promising perspectives of multi-level surgery of the upper airway for obstructive sleep apnea are mentioned, too.

Key words: obstructive sleep apnea, maxillofacial surgery, surgical techniques, maxillomandibular advancement

sleep apnea that has proved effective in bypassing the impaired pharyngeal airway. In 1981, the first uvulopalatopharyngoplasty is carried out in obstructive sleep apnea (2). It increases the pharyngeal cross-sectionbal area and decreases pharyngel collapsibility (3). An enlarged tongue (macroglossia) calls for tongue reduction surgery extending from the midline of the posterior tonge down to the free margin of the epiglottis. The recognition of the importance of tongue position leads to the application of orthognathic surgical principles to obstructive sleep apnea management (4). The technique of geniotubercle advancement is developed for advancing the tongue forwards without changing the lower facial esthetics or the dental occlusion where mandibular dimensions are normal (5). In case of deficient chin, the standard advancement genioplasty ensures esthetic advantages and brings forward the anterior digastric muscle attachments thus effectively providing the forward traction to the hyoid bone and opening-up the hypopharynegal airway (1).

Mandibular advancement surgery using bilateral sagittal split osteotomies is effective in obstructive sleep apnea patients with horiziontal mandibu- 
lar deficience (class II skeletal base) who do not respond to conservative therapy and uvulopalatopharyngoplasty (6).

Although bimaxillary advancement surgery has been originally reserved for obstructive sleep apnea patients with major skeletal deficiencies, the simultaneous advancement of both the maxilla (Le Fort I downfracture osteotomy) and mandible (bilateral sagittal split ramus osteotomy) is becoming a more popular surgical approach to these patients who have failed to respond to other treatment modalities (1).

B. T. Kotecha and A. C. Hall (2014) summarize the current range of surgical treatment options together with the evidence base for their intervention in otolaryngology, maxillofacial and bariatric surgery. According to the surgical site, these authors consider nasal, oropharyngeal, hypopharyngeal, maxillofacial, tracheal and gastric surgical techniques for obstructive sleep apnea. They outline the importance of the radical palatal surgery, the uvulopalatopharyngoplasty, the laser assisted palatoplasty, the radiofrequency thermotherapy of the soft palate and the tongue base, the hyoid suspension, the midline glossectomy, the epiglottic wedge resection, the minimally invasive palatal and tongue base surgery, and the transoral robotic surgery. The advantages of tracheostomy consist in the fact that it bypasses the obstructive segment and remains highly efficient although being invasive and difficult in obese individuals. The bariatric Roux-en-Y gastric bypass provides objective improvement and decreases continuous positive airway pressure while the vertical handed gastroplasty ensures further health benefits (7).

The multi-level surgery of the upper respiratory tract presents with undoubted benefits and efficacy and is a promising option for further progress. Here we should mention the hypoglossal nerve stimulation $(8)$ as well as the hyoid suspension $(9,10)$, the tracheostomy (11), the bariatric surgery (12) and the maxillomandibular advancement.

According to H. D. Ephros et al. (2010), the most commonly performed surgical procedures for snoring and obstructive sleep apnea include nasal reconstruction, uvulopalatopharyngoplasty, advancement genioplasty, mandibular osteotomy with genioglossus advancement and hyoid myotomy and suspension. In more severe cases, maxillomandibular advancement with advancement genioplasty is indicated.
In a systematic review in MEDLINE and Cochrane Library databases with meta-analysis, 21 randomized controlled trials are identified. They deal with maxillomandibular advancement or without with counterclockwise rotation in patients with obstructive sleep apnea (14). There is a statistically meaningful decrease of postoperative apnea-hypopnea index and a statistically meaningful increase of postoperative lowest oxygen saturation values.

Maxillomandibular advancement produces statistically significant airway morphology improvements such as postoperative airway length and airway minimum cross-sectional areas in obstructive sleep apnea patients (15).

The subjective outcomes and use of continuous positive airway pressure after maxillomandibular advancement surgery for obstructive sleep apnea syndrome are evaluated by a self-administered questionnaire completed pre- and postoperatively by 116 patients (16). Surgery is very effective as it decreases snoring by $83 \%$, witnessed apneas by $94 \%$ and continuous positive airway pressure use by $96 \%(\mathrm{p}<0,001)$. The results from a retrospective study of 265 patients with obstructive sleep apnea syndrome and an extremely high apnea-hypopnea index score suggest that this technique is a highly successful one-stage surgery as it eliminates the use of continuous positive airway pressure, improves subjective outcomes and considerably decreases the apnea-hypopnea index score $(\mathrm{p}<0,001)(17)$.

In a prospective randomized study on treatment of obstructive sleep apnea syndrome, anterior-inferior mandibular osteotomy with the purpose of stretching the suprahyoidal muscle is performed in 10 men aged 20 to 65 years, without cardiovascular or neurologic disease, with normal maxillomandibular relation, and with an apnea index between 5 and 25 (18). Initially, there is decreased daytime sleepiness and less snoring after surgery, while after 12 months, apnea index, apnea/hypopnea index, oxygen desaturation index and cephalometric analysis do not show any positive results.

Mandibular retropositioning with or without maxillary advancement is done in a retrospective cohort of 26 patients with sleep-related breathing disorders (19). If this intervention is by $\geq 5 \mathrm{~mm}$, it decreases the posterior airway space below $11 \mathrm{~mm}$ (in $30,75 \% ; p=0,03$ ) and proves evidence of soft palate elongation by $>32 \mathrm{~mm}$ (in $15,39 \%$ of the cases; $p=0,037$ ). Postoperative polysomnography 
displays a higher incidence of mild to moderate obstructive sleep apnea syndrome in patients after mandibular retropositioning $\geq 5 \mathrm{~mm}$ (in 69,25\%) compared to those with mandibular retropositioning in combination with maxillary advancement (in $38,46 \%$ of the cases; $p=0,039$ ).

The analysis of 30 adult patients at a mean age of 50,5 $\pm 9,6$ years indicates that maxillomandibular advancement is a clinically effective and safe long-term treatment modality for most patients with moderate-to-severe obstructive sleep apnea as demonstrated by significant diminutions in apneahypopnea index, diastolic blood pressure and subjective sleepiness, with concomitant significant quality of life improvement (20).

In a retrospective cohort study of 88 obstructive sleep apnea patients undergoing maxillomandibular advancement, the volume of perioperative fluids administered is not significantly associated with increased hospital stay length; however, it might be related to the presence of postoperative complications (21).

During a 9-year study period, 25 obstructive sleep apnea patients have undergone maxillomandibular advancement and genial tubercle advancement (22). The mean maxillary and mandibular advancements (T1 versus T0) are 9,8 $\mathrm{mm}$ (range, 1,6-15,2 mm) and $10,85 \mathrm{~mm}$ (range, 6,3-15,8 $\mathrm{mm}$ ), respectively. The maxillomandibular complex advancement by $10 \mathrm{~mm}$ remains stable at a mean follow-up period longer than two years and preoperative orthodontic treatment does not influence skeletal stability.

The maxillomandibular advancement improves systemic blood pressure in 51 obstructive sleep apnea subjects at a mean of $44 \pm 8$ years and with a mean body mass index of $29 \pm 3,4 \mathrm{~kg} / \mathrm{m}^{2}$ - from $131 \pm 12,6 \mathrm{~mm} \mathrm{Hg}$ down to $127 \pm 12,5 \mathrm{~mm} \mathrm{Hg}$; p $<0,001$, particularly in those with established artertial hypertension (23). Thus such a surgery is more effective for this cardiovascular disease than other management modalities.

The following clinical recommendations when considering skeletal surgery in preadolescent obstructive sleep apnea patients are suggested (24): i) the decision criteria of maxillomandibular advancement surgery as definite treatment; ii) the proper surgical design for both maximal airway enlargement and esthetic improvement, and iii) the postoperative facial growth for long-term stability of airway function and skeletal improvement.
The current technique for large maxillomandibular advancements designed for obstructive sleep apnea utilizes plates, screws, Erich Arch Bar and suspension wires which are left in place for five-six weeks (25). Guiding elastics are worn for the first week. This new technique yields a success rate over $90 \%$ for patients with a body mass index $<40 \mathrm{~kg} / \mathrm{m}^{2}$ and $81 \%$ for those with a body mass index $\geq 40 \mathrm{~kg} / \mathrm{m}^{2}$. The large advancements during maxillomandibular advancement surgeries can help improve postoperative obstructive sleep apnea outcomes.

The anterior mandibular subapical setback osteotomy combined with bilateral sagittal split osteotomy in the treatment of selected obstructive sleep apnea patients enables maximal mandibular advancement, alleviates pharyngeal narrowing and minimizes the alteration to the mid facial profile that is associated with the traditional maxillomandibular advancement (26).

Mandibular wing osteotomy is carried out in 10 subjects at a mean age of $37,8 \pm 7,26$ years with apnea-hypopnea index $>15$, previously unresponsive conservative treatment for the obstructive sleep apnea, moderate to severe retrognathia and no suggested conventional orthognathic surgery because of dentition or lack of willingness (27). One year after operation, there is a significant change in the Epworth Sleepiness Scale score and in the apnea-hypopnea index as well.

The retrospective search in PubMed and in Scopus identifies 18 articles with 522 obstructive sleep apnea patients treated with three glossectomy techniques such as midline glossectomy, lingual plasty and submucosal minimally invasive lingual excision (28). The glossectomy significantly improves sleep outcomes as part of multi-level surgery in such adult patients, e. g. the apnea-hypopnea index $(\mathrm{p}<0,0001)$, the Epworth Sleepiness Scale score $(\mathrm{p}<0,00001)$, the snoring visual analogue scale $(\mathrm{p}<0,0001)$ and lowest $\mathrm{O}_{2}$ saturation $(\mathrm{p}<0,0001)$. Surgical success rate is $59,6 \%$ and surgical cure is achieved in $22,5 \%$ of the cases.

A modification of the conventional genioglossus advancement previously described by R. W. Riley et al. (1987) consists in bone segment replacement at the mandibular basal bone rather than at the mid area of the symphysis (29). This means a linear movement that allows a greater advancement and avoids the rotation of the genioglossus muscle. The advantages of this surgical technique include great- 
er effectiveness, stability, more pleasing esthetic outcome and reduction of potential complications. In 13 male obstructive sleep apnea patients at an average age of $43,0 \pm 2,4$ years and with an average follow-up of $18,0 \pm 3,6$ months, the combination of elliptical window genioglossus advancement, hyoid bone suspension and uvulopalatopharyngoplasty results in statistically significant differences between mean pre- and postoperative apneahypopnea index $(28,3$ versus 12,$1 ; \mathrm{p}<0,05)$ and Epworth Sleepiness Scale score (15,2 versus 6,3; $\mathrm{p}<0,05)(30)$.

In obstructive sleep apnea patients, upper airway may be opened by an advancement genioplasty, but this may compromise facial esthetics by over-projecting the chin prominence. A modified genioplasty is presented in order to overcome this difficulty (31). It enables a rotational repositioning allowing for advancement of the genioglossus attachments as well as it avoids an excessive projection of pogonion, which would otherwise result in an unfavourable profile.

Distraction osteogenesis is applied in 15 patients with obstructive sleep apnea and temporomandibular joint ankylosis (32). Rate of distraction is $1 \mathrm{~mm} /$ day for adults and $2 \mathrm{~mm} /$ day for children till the mandibular incisors are in reverse overjet. After distraction, Epworth Sleepiness Scale score improves from a mean of 10,25 to 2,25 , apnoea-hypopnoea index - from 57,03/hour to $6,67 /$ hour, lowest oxygen saturation - from $64,47 \%$ to $81,20 \%$, average minimum oxygen saturation - from $92,17 \%$ to $98,19 \%$ and body mass index - from a mean of $18,26 \mathrm{~kg} / \mathrm{m}^{2}$ to $21,39 \mathrm{~kg} / \mathrm{m}^{2}$.

This method is a less invasive surgical technique in the management of obstructive sleep apnea, secondary to temporomandibular joint ankylosis (33). It treats not only the sleep breathing disorder but also corrects the facial asymmetry at the same time.

Bilateral mandibular distraction osteogenesis for obstructive sleep apnea is used in 37 patients (34). Of them, 20 subjects are treated with external and 17 ones with internal distraction devices. The average mandibular elongation is $30 \mathrm{~mm}$ in the first group versus $22 \mathrm{~mm}$ in the second one, however, there is a greater risk for pin tract infection $(27,5 \%$ versus 5,88\%). In addition, pin loosening in $22,5 \%$ of the cases requires pin replacement or leads to reduced retention period. The internal devices have a precise and predictable vector of lengthening and left less visible scars at the submandibular area, however, they carry the disadvantage of requiring a second operation for device removal.

The comparative evaluation of the effectiveness and safety of two tongue base suspension techniques (Repose $\left({ }^{\circledR}\right)$ system and modified tongue base suspension) with or without uvulopalatopharyngoplasty in obstructive sleep apnea as reported in several studies covering a total of 413 patients indicates that modified tongue base suspension is associated with significantly higher success rates $(73,7 \%$ versus $56,7 \% ; p<0,001)(35)$. The results from the application of uvulopharyngopalatoplasty plus tongue base suspension with or without septoplasty in 61 obstructive sleep apnea patients demonstrate that the mean obstructive apnea duration is the sole variable with a significant and satisfactory area under the curve value $(p=0,003)(36)$. The cutoff value is $26,75 \mathrm{sec}$ with $71,4 \%$ sensitivity; $72,1 \%$ specificity; $88,0 \%$ positive predictive value and $46,9 \%$ negative predictive value. Univariate analysis reveals an association between surgical failure and mean obstructive apnea duration $>$ $26,75 \mathrm{sec}$, total apnea duration, lowest $\mathrm{O}_{2}$ saturation, mean $\mathrm{O}_{2}$ saturation, mean $\mathrm{O}_{2}$ desaturation and oxygen desaturation index, although only mean obstructive apnea duration $>26,75 \mathrm{sec}$ remains an independent predictor for unfavourable outcome after adjustment for other confounders in multivariate analysis $(p=0,041)$. Therefore, the patients with longer obstructive apnea duration are at risk of having surgical failure.

Transoral robotic surgery is a useful and effective tool in nine children at a mean age of 10,5 years (range, 5,2-18,5) years with obstructive sleep apnea/hypopnea syndrome associated with base of tongue and lingual tonsillar hypertrophy (37). There are statistically significant postoperative reductions of the apnea-hypopnea index $(p \leq 0,05)$, hypopneic events $(p<0,05)$ and lowest oxygen saturation $(\mathrm{p} \leq 0,01)$.

The subjective perception of facial appearance after maxillofacial surgery for obstructive sleep apnea is evaluated in 26 patients at a mean age of $45 \pm 7$ years (38). Postoperatively, 14 patients $(53,85 \%)$ indicate that their facial appearance has improved, four patients $(15,38 \%)$ record a neutral score, and eight patients $(30,77 \%$ of the cases) report a lower score. These ratings do not correlate with changes neither in the apnea-hypopnea index, nor in the Epworth Sleepiness Scale following surgery. 
The results from a retrospective cohort analysis of 267 consecutive patients with obstructive sleep apnea reveal two early major medical complications after intrapharyngeal surgical management among 162 patients and four complications after extrapharyngeal surgery among the rest 105 patients (39). There are statistically significant differences only for mean age, apnea-hypopnea index, Epworth Sleepiness Scale score, minimum nocturnal oxygen saturation and body mass index

between the surgical groups.

According to L. Spicuzza et al. (2015), the mandibular advancement devices, particularly if custom made, are effective in mild to moderate obstructive sleep apnea. Uvulopalatopharyngoplasty is a well-established procedure if continuous positive airway pressure is not tolerated, whereas maxillarmandibular surgery can be suggested to patients with a craniofacial malformation. A number of minimally invasive procedures to treat snoring are currently under evaluation. A multidisciplinary approach is necessary for an accurate management of the disease.

\section{References}

1. Dimitroulis G. Obstructive sleep apnoea: the role of the oral and maxillofacial surgeon. Aust Dent J. 1997; 42(1): 25-29.

2. Fujita S, Conway W, Zorick F, Roth T. Surgical correction of anatomic abnormalities in obstructive sleep apnea syndrome: uvulopalatopharyngoplasty. Otolaryngol Head Neck Surg. 1981; 89(6): 923-934

3. Schwartz AR, Schubert N, Rothman W, Godley F, Marsh B, Eisele D, et al. Effect of uvulopalatopharyngoplasty on upper airway collapsibility in obstructive sleep apnea. Am Rev Respir Dis. 1992; 145(3): 527-532.

4. Riley RW, Powell NB, Guilleminault C. Maxillary, mandibular, and hyoid advancement for treatment of obstructive sleep apnea: a review of 40 patients. J Oral Maxillofac Surg. 1990; 48(1): 2026

5. Riley RW, Powell N, Guilleminault C. Current surgical concepts for treating obstructive sleep apnea syndrome. J Oral Maxillofac Surg. 1987; 45(2): 149-157.

6. Sarver DM. The role of orthodontics in the surgical treatment of obstructive sleep apnea. Oral and maxillofacial treatment of obstructive sleep apnea. Oral Maxillofac Surg Clin North Am. 1995; 7: 311-326.

7. Kotecha BT, Hall AC. Role of surgery in adult obstructive sleep apnoea. Sleep Med Rev. 2014; 18(5): 405-413.

8. Kezirian EJ, Boudewyns A, Eisele DW, Schwartz AR, Smith PL, Van de Heyning PH, De Backer WA. Electrical stimulation of the hypoglossal nerve in the treatment of obstructive sleep apnea. Sleep Med Rev. 2010; 14(5): 299-305.

9. Bowden MT, Kezirian EJ, Utley D, Goode RL. Outcomes of hyoid suspension for the treatment of obstructive sleep apnea. Arch Otolaryngol Head Neck Surg. 2005; 131(5): 440-445.

10. Нцrmann K, Baisch A. Hyoid suspension in rhinologic and sleep apnoea surgical techniques. In: Kountakis SE, Onerci M, eds. Rhinologic and sleep apnoea surgical techniques. $1^{\text {st }}$ ed. Heidelberg: Springer Verlag, 2007: 355-360.

11. Thatcher GW, Maisel RH. The long-term evaluation of tracheostomy in the management of severe obstructive sleep apnea. Laryngoscope. 2003; 113(2): 201-204.

12. Haines KL, Nelson LG, Gonzalez R, Torrella T, Martin T, Kandil A, et al. Objective evidence that bariatric surgery improves obesity-related obstructive sleep apnea. Surgery. 2007; 141(3): 354-358.

13. Ephros HD, Madani M, Yalamanchili SC. Surgical treatment of snoring \& obstructive sleep apnoea. Indian J Med Res. 2010; 131: $267-276$

14. Knudsen TB, Laulund AS, Ingerslev J, Нотше P, Pinholt EM. Improved apnea-hypopnea index and lowest oxygen saturation after maxillomandibular advancement with or without counterclockwise rotation in patients with obstructive sleep apnea: a meta-analysis. J Oral Maxillofac Surg. 2015; 73(4): 719-726.

15. Butterfield KJ, Marks PL, McLean L, Newton J. Pharyngeal airway morphology in healthy individuals and in obstructive sleep apnea patients treated with maxillomandibular advancement: a comparative study. Oral Surg Oral Med Oral Pathol Oral Radiol. 2015; 119(3): 285-292.

16. Goodday R, Bourque S. Subjective outcomes of maxillomandibular advancement surgery for treatment of obstructive sleep apnea syndrome. J Oral Maxillofac Surg. 2012; 70(2): 417-420.

17. Goodday RH, Bourque SE, Edwards PB. Objective and subjective outcomes following maxillomandibular advancement surgery for treatment of patients with extremely severe obstructive sleep apnea (apnea-hypopnea index >100). J Oral Maxillofac Surg. 2015 Jul 26. doi: 10.1016/j.joms.2015.07.016.

18. Krekmanov L, Andersson L, Ringqvist M, Wilhelmsson B, Walker-Engstrцm ML, Tegelberg A, et al. Anterior-inferior mandibular osteotomy in treatment of obstructive sleep apnea syndrome. Int J Adult Orthodon Orthognath Surg. 1998; 13(4): 289-298.

19. Demetriades N, Chang DJ, Laskarides C, Papageorge M. Effects of mandibular retropositioning, with or without maxillary advancement, on the oro-naso-pharyngeal airway and development of sleep-related breathing disorders. J Oral Maxillofac Surg. 2010; 68(10): 2431-2436.

20. Boyd SB, Walters AS, Waite P, Harding SM, Song Y. Long-term effectiveness and safety of maxillomandibular advancement for treatment of obstructive sleep apnea. J Clin Sleep Med. 2015; 11(7): 699-708.

21. Ettinger KS, Wyles CC, Bezak BJ, Yildirim Y, Arce K, Viozzi $\mathrm{CF}$. Impact of perioperative fluid administration on postoperative morbidity and length of hospital stay following maxillomandibular advancement for obstructive sleep apnea. J Oral Maxillofac Surg. 2015; 73(7): 1372-1383.

22. Lee SH, Kaban LB, Lahey ET. Skeletal stability of patients undergoing maxillomandibular advancement for treatment of obstructive sleep apnea. J Oral Maxillofac Surg. 2015; 73(4): 694-700.

23. Islam S, Taylor CJ, Ormiston IW. Effects of maxillomandibular advancement on systemic blood pressure in patients with obstructive sleep apnoea. Br J Oral Maxillofac Surg. 2015; 53(1): 34-38. 
24. Ahn HW, Lee BS, Kim SW, Kim SJ. Stability of modified maxillomandibular advancement surgery in a patient with preadolescent refractory obstructive sleep apnea. J Oral Maxillofac Surg. 2015; 73(9): 1827-1841.

25. Camacho M, Liu SY, Certal V, Capasso R, Powell NB, Riley RW. Large maxillomandibular advancements for obstructive sleep apnea: An operative technique evolved over 30 years. J Craniomaxillofac Surg. 2015; 43(7): 1113-1118.

26. Islam S, Ormiston IW. Innovative use of anterior subapical setback combined with bilateral sagittal split osteotomy in patients with obstructive sleep apnoea. Br J Oral Maxillofac Surg. 2015; 53(1): 89-91.

27. Tabrizi R, Pourdanesh F, Soleimanpour M, Shafie E. Evaluation of mandibular wing osteotomy in obstructive sleep apnea cases with retrognathia. J Maxillofac Oral Surg. 2015; 14(1): 46-50.

28. Murphey AW, Kandl JA, Nguyen SA, Weber AC, Gillespie MB. The effect of glossectomy for obstructive sleep apnea: a systematic review and meta-analysis. Otolaryngol Head Neck Surg. 2015; 153(3): 334-342.

29. Garcна Vega JR, de la Plata MM, Galindo N, Navarro M, Dнеz D, Loncara F. Genioglossus muscle advancement: A modification of the conventional technique. J Craniomaxillofac Surg. 2014; 42(3): 239-244.

30. Cillo JE Jr, Dalton PS, Dattilo DJ. Combined elliptical window genioglossus advancement, hyoid bone suspension, and uvulopalatopharyngoplasty decrease apnea hypopnea index and subjective daytime sleepiness in obstructive sleep apnea. J Oral Maxillofac Surg. 2013; 71(10): 1729-1732.

31. Heggie AA, Portnof JE, Kumar R. The rotational genioplasty: a modified technique for patients with obstructive sleep apnoea. Int J Oral Maxillofac Surg. 2015; 44(6): 760-762.

32. Yadav R, Bhutia O, Shukla G, Roychoudhury A. Distraction osteogenesis for management of obstructive sleep apnoea in temporomandibular joint ankylosis patients before the release of joint. J Craniomaxillofac Surg. 2014; 42(5): 588-594.

33. Gaur A, Singh G, Mishra M, Srivatsan KS, Sachdev V. Distraction osteogenesis for management of obstructive sleep apnea secondary to TMJ ankylosis. Natl J Maxillofac Surg. 2013; 4(1): 104-106.

34. Rachmiel A, Nseir S, Emodi O, Aizenbud D. External versus internal distraction devices in treatment of obstructive sleep apnea in craniofacial anomalies. Plast Reconstr Surg Glob Open. 2014; 2(7): e188.

35. Bostanci A, Turhan M. A systematic review of tongue base suspension techniques as an isolated procedure or combined with uvulopalatopharyngoplasty in obstructive sleep apnea. Eur Arch Otorhinolaryngol. 2015 Oct 27.7 p.

36. Bostanci A, Bozkurt S, Turhan M. The relationship between the duration of obstructive respiratory events and outcomes of multilevel upper airway surgery in patients with obstructive sleep apnea. Eur Arch Otorhinolaryngol. 2015 Sep 14. doi: 10.1007/ s00405-015-3781-3788.

37. Thottam PJ, Govil N, Duvvuri U, Mehta D. Transoral robotic surgery for sleep apnea in children: Is it effective? Int J Pediatr Otorhinolaryngol. 2015 Oct 17. doi: 10.1016/j.ijporl.2015.10.010.

38. Islam S, Aleem F, Ormiston IW. Subjective assessment of facial aesthetics after maxillofacial orthognathic surgery for obstructive sleep apnoea. Br J Oral Maxillofac Surg. 2015; 53(3): 235-238.

39. Cillo JE Jr, Dattilo DJ. Early major medical complications after surgical management of obstructive sleep apnea: a retrospective cohort analysis and case series. J Oral Maxillofac Surg. 2015; 73(1): 123-128.

40. Spicuzza L, Caruso D, Di Maria G. Obstructive sleep apnoea syndrome and its management. Ther Adv Chronic Dis. 2015; 6(5): 273-285. 